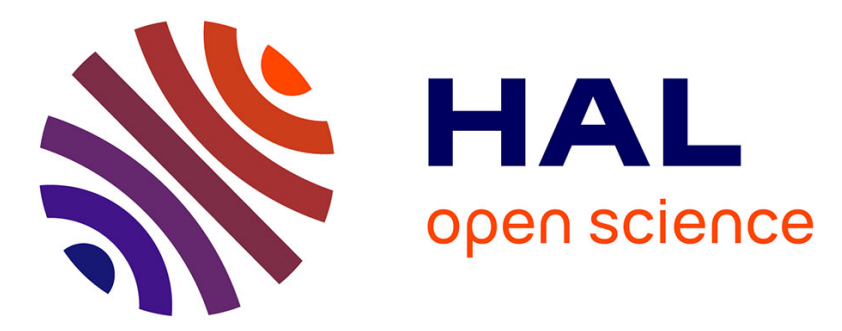

\title{
Comparing BIM in Construction with 3D Modeling in Shipbuilding Industries: Is the Grass Greener on the Other Side?
}

Ran Luming, Vishal Singh

\section{- To cite this version:}

Ran Luming, Vishal Singh. Comparing BIM in Construction with 3D Modeling in Shipbuilding Industries: Is the Grass Greener on the Other Side? 12th IFIP International Conference on Product Lifecycle Management (PLM), Oct 2015, Doha, Qatar. pp.193-202, 10.1007/978-3-319-33111-9_18 . hal-01377443

\section{HAL Id: hal-01377443 \\ https://hal.inria.fr/hal-01377443}

Submitted on 7 Oct 2016

HAL is a multi-disciplinary open access archive for the deposit and dissemination of scientific research documents, whether they are published or not. The documents may come from teaching and research institutions in France or abroad, or from public or private research centers.
L'archive ouverte pluridisciplinaire HAL, est destinée au dépôt et à la diffusion de documents scientifiques de niveau recherche, publiés ou non, émanant des établissements d'enseignement et de recherche français ou étrangers, des laboratoires publics ou privés. 


\title{
Comparing BIM in construction with 3D modeling in shipbuilding industries: Is the grass greener on the other side?
}

\author{
Ran Luming ${ }^{1}$, Vishal Singh ${ }^{2}$, \\ ${ }^{1}$ Department of Industrial Engineering and Management, Aalto University, Finland \\ Luming.Ran@aalto.fi \\ ${ }^{2}$ Department of Civil and Structural Engineering, Aalto University, Finland \\ Vishal.Singh@aalto.fi
}

\begin{abstract}
Building Information Modelling (BIM), as an object-oriented tool, has been the buzzword in Architecture Engineering and Construction (AEC) sector in recent years. The buzz has created a lot of promise of an imminent paradigm shift and productivity and lifecycle improvements in the AEC sector, and plenty of benefits are cited in the literature. Consequently, the word has reached the shipbuilding industry as well, which faces many similar productivity and lifecycle challenges as the AEC industry, and which is seeking similar advancements in digital tools that can bring around the change. As a result, the Finnish shipbuilding industry expressed interest in exploring what are the BIM-enabled best practices in the AEC sector, and which of these can potentially be transferred to the shipbuilding industry. This research explored these issues. Findings suggest that due to lack of mutual communication, the professionals across each industry believe the other to be doing better.
\end{abstract}

Keywords: BIM, PLM, 3D CAD, AEC, shipbuilding

\section{Introduction}

Building information modeling (BIM) provides not only an advanced design tool, but also an efficient management tool for the Architecture Engineering and Construction (AEC) sector. Consequently, BIM adoption in the AEC industry has significantly increased in recent years ( $\mathrm{Lu} \mathrm{\&} \mathrm{Li}, 2011$ ), both globally as well as in Finland. At the same time, the European (including Finnish) shipbuilding industry has undergone a fundamental shift from a labor-intensive industry to a capital and knowhow dominated high-tech industry (Tholen and Ludwig, 2006). A large number of software and CAD tools are used in each stage of the design process to evaluate a variety of characteristics and life phases (Whitfield et al., 2003, Li et al., 2011). Despite the demonstrated benefits of 3D CAD tools, certain limitations of CAD tools have hindered the development of the design process in shipbuilding industry, which is actively searching for better solutions. In such a scenario, given several similarities between the AEC and shipbuilding industry (e.g., complex engineering 
processes, multidisciplinary team members, and long delivery times), the Finnish shipbuilding industry expressed interest in learning from the AEC industry, especially given the buzz around BIM. Therefore, this research mainly aims at: (1) exploring the realized practical benefits of BIM in AEC industry and (2) studying whether BIM can be a potential solution to improve the productivity of shipbuilding projects.

Although BIM has been widely promoted, it is agreed that there are gaps between the potential benefits and what has been realized in practice so far (e.g. $\mathrm{Lu} \mathrm{\&} \mathrm{Li}$, 2011, Barlish and Sullivan, 2012). Therefore, in order to understand how BIM can potentially benefit shipbuilding industry, it is important to understand how it actually benefits AEC industry in practice. That is, rather than looking at potential benefits of $\mathrm{BIM}$ reported in the literature, this research only focuses on BIM-enabled practices (BEPs) that have already been demonstrated to be beneficial in AEC projects. In order to assess which BEPs can be adapted to improve the productivity of shipbuilding projects, it is important to understand (1) the current state of 3D CAD tools in shipbuilding industry, (2) the views of shipbuilding professionals, and (3) which BEPs can potentially be transferred to improve the efficiency of shipbuilding process.

\section{Background}

Benefits of BIM in AEC industry. There are numerous studies on the benefits of BIM (CRC, 2007; Azhar, 2011; Barlish \& Sullivan, 2012; Becerik-Gerber \& Rice, 2010). Some of key benefits include: faster and effective processes, reduced rework, visualization, information sharing and reusability; better design; controlled wholelife costs and environmental data; better production quality and sequencing; automated assembly; better client service scheduling, sequencing coordination, etc.

The adoption of Industrial Foundation Class (IFC) as an open-data standard BIM file format has increased the interoperability among AEC/FM software applications, and promoted object-oriented 3D models that contain lifecycle information of building elements. With an object-oriented approach, BIM extends the capability of traditional 3D CAD approach by defining and applying intelligent relationships between the elements in the building model (Singh et al., 2011). The information management capabilities and inbuilt intelligence allow resolving conflicts, speed up solutions, and keep projects on time and on budget. Continuous, accurate, and realtime information sharing among project participants is the key, and BIM is seen as an enabler (Becerik-Gerber \& Rice, 2010), both as a set of tools and processes (Succar, 2009; Autodesk, 2014; NBIMS-US, 2015). Several studies have reported economic benefits from the utilization of BIM in AEC projects. For instance, Becerik-Gerber and Rice (2010) found that 55 percent of the respondents said BIM helped cut project costs; and 58 percent found that overall project duration was reduced by up to 50 percent.

As with the AEC industry, and unlike other industries such as automobile or aircraft, Shipbuilding has an individual nature. Mass production is rather seldom (Solesvik, 2007), and ships are made according to the concept of "multi-kinds, smallamount production" (Roh \& Lee, 2007a). Therefore, the design and production details 
are almost different every time (Okumoto et al., 2009). Similarly, the ship manufacturing processes show complex patterns over a long period of time (Kim et al., 2002), and ships are constructed using blocks. Each block is designed and then assembled in the assembly shop near the dock. Large blocks (i.e., erection blocks) are made by joining several blocks together. Finally, large blocks are moved to the dock and welded together to form an entire ship (Kim et al., 2015). As noted by Roh and Lee $(2007 \mathrm{~b})$ in their overview of shipbuilding process, "essentially, the manufacturing process of ship is similar to that of a large product by use of Lego blocks".

A large number of software tools are used in each stage of the design process to evaluate a variety of characteristics and life phases (Whitfield et al., 2003). CAD software is used to increase the productivity of the designer, improve the quality of design, improve communications through documentation, and to create a database for manufacturing (Sarcar et al., 2008). Different CAD systems are used by different design stages and departments (Tann and Shaw, 2007, Baba and Nobeoka, 1998).

Benefits of 3D CAD in shipbuilding. In general, 3D CAD contributes to more efficient ship design through, but not limited to 3D visualization, design simulation and interference checking. 3D CAD is used to perform simulation analysis of such problem as thermal, mechanical stress and vibration (Baba and Nobeoka, 1998). Interference-checking (i.e., collision detection) can also be carried out using 3D CAD tools (Okumoto, 2009). Communication and coordination for collaborative design process and concurrent engineering, including with manufacturing engineers (Solesvik, 2007, Baba and Nobeoka, 1998), are also facilitated by 3D CAD.

Limitations of 3D CAD in shipbuilding. It is argued that certain limitations of CAD tools have hindered further development of shipbuilding design process. These include: (1) The lack of interoperability among different CAD systems: While various data formats (international standards) have been studied and discussed in the industry, there is still no open standard widely shared by major CAD vendors in the shipping industry, and (2) The inability of CAD tools to support initial design: While 3D models are used in the detailed design stage, the early design stage is typically based on 2D drawings (Alsonso et al., 2013).

\section{Methodology}

Following the literature review, more in-depth first-hand data on the benefits of BIM in AEC industry and the current state of $3 \mathrm{D}$ CAD in shipbuilding industry were collected through qualitative interviews. Seven BIM experts from AEC industry and seven shipbuilding professionals were invited to interviews. Professional backgrounds of the interviewees are shown in Table 1 and Table 2. Notes were taken during all the interviews, as well as recordings. Each interview lasted from 40 to 100 minutes. Each interview was transcribed word by word and emailed to the interviewees for proofreading before the analyses started. In general, the following four steps were taken in the development of the empirical study: 
1 Seven Interviews with BIM experts from Finnish AEC industry were carried out to identify BEPs.

2 Based on step 1, a list of best BEPs was identified, and the top four BEPs were studied further.

3 Seven interviews with shipbuilding professionals were carried out to (1) explore the current state of 3D CAD in Finnish shipbuilding industry, and (2) identify areas that need further development.

4 Based on the results of the first three steps, discussion was carried out to identify which BEPs could be potentially transferred to shipbuilding industry to improve the productivity.

Table 1. Backgrounds of seven BIM experts and companies they represent

\begin{tabular}{lll}
\hline & Interviewee title & \multicolumn{2}{c}{ Company } \\
\hline 1 & General Manager, contractor & $\begin{array}{l}\text { A: a consultant and IT developer for } \\
\text { building industry, specialized in BIM } \\
\text { services and solutions }\end{array}$ \\
\hline 2 & $\begin{array}{l}\text { BIM process consultant \& Chair of } \\
\text { buildingSmart Finland }\end{array}$ & B: Distributor of BIM software \\
\hline 3 & BIM software Specialist & C: Finland's second-largest university \\
\hline 4 & BIM Professor and researcher & D: BIM software developer \\
\hline 5 & Senior Vice President & E: Large construction group \\
\hline 6 & Vice President, $R \& D$ & F: Design and energy BIM models \\
\hline 7 & Director, Innovation and Development & Int
\end{tabular}

The interviews were semi-structured. Same seven open-ended questions were asked to all the interviewees to capture their understanding of BEPs. The 7 interview questions are listed below:

1. What is your background?

2. What is your company's basic information?

3. What is your company's role in BIM industry?

4. What are the most important benefits of BIM that you have seen in practice?

5. What are the benefits of BIM that you have seen divided by each stage of a typical AEC project (e.g., design, construction and operation)?

6. How do the successful companies realize these benefits through practices?

7. Which practices can be transferred to shipbuilding?

The second group of interviews were carried out in a similar manner as the first group. Seven interview questions were formed, aiming at finding out whether these identified BEPs could be transferred or not.

Table 2. Backgrounds of seven shipbuilding professionals and companies they represent

\begin{tabular}{c|c|c|c}
\hline \multicolumn{2}{c}{ Interviewee title } & Specialized area & Company \\
\hline 8 & $\begin{array}{c}\text { CAD and PLM } \\
\text { Development Manager }\end{array}$ & $\begin{array}{c}\text { HVAC engineering } \\
\text { design development }\end{array}$ & $\begin{array}{c}\text { G: shipyard in } \\
\text { Finland, specialized in }\end{array}$ \\
\hline
\end{tabular}




\begin{tabular}{|c|c|c|c|}
\hline 9 & $\begin{array}{l}\text { Designer, Electrical } \\
\text { Design }\end{array}$ & $\begin{array}{l}\text { Electrical design, cable } \\
\text { routing, } 3 D \text { administration } \\
\& 3 D \text { modeling }\end{array}$ & \multirow{3}{*}{$\begin{array}{l}\text { building cruise ships, } \\
\text { car-passenger ferries, } \\
\text { technically demanding } \\
\text { special vessels and } \\
\text { offshore projects. }\end{array}$} \\
\hline 10 & $\begin{array}{c}C A D \text { Administrator, } \\
\text { HVAC and Catering design }\end{array}$ & $3 D$ modeling & \\
\hline 11 & $\begin{array}{l}\text { Head of Design \& } \\
\text { Engineering }\end{array}$ & $\begin{array}{l}\text { Naval architecture, } P M \text {, } \\
\text { operations management }\end{array}$ & \\
\hline 12 & $\begin{array}{l}\text { Chief software } \\
\text { administrator }\end{array}$ & $\begin{array}{l}\quad \text { Shipbuilding design } \\
\text { software administration and } \\
\text { training }\end{array}$ & \multirow{2}{*}{$\begin{array}{l}\quad H \text { : leading } \\
\text { European consulting } \\
\text { and eng. company. } \\
\text { Offers design, } \\
\text { engineering, PM } \\
\text { services to clients in } \\
\text { the marine industry. }\end{array}$} \\
\hline 13 & $\begin{array}{l}\text { Senior VP, business } \\
\text { development }\end{array}$ & $\begin{array}{l}\text { Naval architecture, } \\
\text { project management, } \\
\text { project engineering }\end{array}$ & \\
\hline 14 & Senior Sales Manager & $\begin{array}{l}\quad \text { Ship \& Plant 3D Design, } \\
\text { Project and Information } \\
\text { management solutions. }\end{array}$ & $\begin{array}{l}\text { I: developer and } \\
\text { supplier of } 3 D \text { software } \\
\text { for the plant- and ship } \\
\text { building industries. }\end{array}$ \\
\hline
\end{tabular}

The 7 interview questions are listed below:

1. What is your background?

2. What is your company's basic information?

3. What is your company's role in shipbuilding industry?

4. Is there any integrated solution of different design models?

5. Is object-oriented 3D model used in shipbuilding?

6. What are the benefits or practices enabled by the integrated solution or object-oriented 3D model?

7. Which of these listed practices have been applied in shipbuilding already?

\section{Results}

BIM-enabled practices in Finland. The top four most frequently mentioned BEPs are: (1) Collision/Clash detection, (2) Visualization, (3) Quantity take-off, and (4) Scheduling. These practices were commonly accepted and widely recognized by the seven interviewees as the best and thus were studied further.

Clash detection has been widely understood as the main reason for companies in AEC industry to start using BIM from the beginning. It is also one of the most extensively used features of BIM. However, it is important to differentiate between clash detection and collision detection. It was noted that during the interviews and often in reality, people in AEC industry use collision detection and clash detection interchangeably. In contrast, there is a subtle but important difference between these two concepts. Collision detection is the process of identifying incongruous objects in different models that are found to be occupying the same space in the master, whereas clash detection can also refer to clashes in scheduling of activities, for example, order 
of assembly. Similarly, clashes in rules can also be identified. In general, there are three types of clashes in a typical construction project, i.e., hard clash, soft clash/clearance clash and 4D/workflow clash. Therefore, collision detection only refers to the detection of hard clash. In the context of this research, the term clash detection is used to cover all three types of clashes.

BIM-enabled $3 D$ visualization is the second frequently mentioned BEP during the interviews with the AEC professionals. Besides design visualizations, since BIM produces accurate and detailed building models, these models can also be used for advanced visualizations, such as creating images for in process-design reviews, lighting simulations, and highly polished marketing materials (Autodesk, 2008). Accurate design visualizations produced by BIM tools contributes to open communication within the design team, facilitating shared understanding of designs. $3 \mathrm{D}$ visualization also contributes to more efficient external communication with the client. During the construction process, 3D visualization also benefits both site supervisor, and construction worker.

Quantity takeoff (QTO) was the third most frequently discussed BEP. It directly influences the accuracy of cost estimation, including counting the number of items associated with a particular construction project, determining the associated materials and labor costs, and formulating a bid (or estimate) as part of the bidding process.

The fourth frequently mentioned BEP during the interviews was project scheduling, which is one of the key processes during the development of construction projects. This function of BIM is commonly called the 4th dimension of BIM. 4D BIM allows the integration of traditional CPM Gantt chart visualization methods of schedules with 4D visualizations and line-of-balance visualizations (Rogier \& Olofsson, 2007) to support location-based management (Kenley 2006).

3D CAD in Finnish shipbuilding industry: "One CAD" solution. Based on the interview results with the shipbuilding professionals, it can be concluded that ship design is generally carried out through One CAD solution. It means that different ship design disciplines are using the same $\mathrm{CAD}$ tool or CAD tools from the same software vendor. There is no widely accepted standard like IFC in AEC industry. By using the same CAD tool for different design disciplines, interoperability issues are reduced.

The situation in Company $\mathrm{G}$ is slightly different. Several designs tools are used by different disciplines such as hull, outfitting and interior. Both hull and outfitting designs are conducted in 3D. Since Company G is specialized in building cruise ships, interior design is also one of the key design disciplines, but interior design is carried out with 2D CAD tool. Consequently, models built by different design tools (in different data format) need to be first converted manually into one single format, once a week. Once the hull model is integrated into the outfitting model, the rest of modelling work is carried out in the integrated model.

\section{Benefits of the One CAD solution}

Several benefits of the One CAD solution were mentioned by the interviewees. In general, the benefits can be divided into two groups, i.e., benefits of using advanced $3 \mathrm{D}$ CAD tools and benefits of using the same CAD tool/CAD tools from the same vendor throughout the project (i.e., the One $\mathrm{CAD}$ solution). By using contemporary 3D CAD tools, information-rich 3D models can be easily generated. These models are not merely a $3 \mathrm{D}$ visualizations of objects, but also contains up-to-date information relevant to the objects. 
$3 D$ models enabled better design coordination: The 3D models enable much more direct comprehension of design intentions than ambiguous and complex 2D drawings. Everyone involved in the project can get a clear view of the designs and avoid misunderstanding. 3D visualizations also enable workers to better understand the relationship between different areas/systems of the ship.

$3 D$ models enabled better work planning: In shipbuilding, the main phases such as detail design, procurement, production etc. are carried out concurrently. 3D models help to improve work efficiency by enabling them to understand the status of ongoing work and plan for work in advance. With 3D models, workers can better plan their work before the actual work starts, and get familiar with the surroundings.

Easy and accurate quantity takeoff: A bill of materials can be exported directly from 3D models, which lists quantities of all the materials needed for assembly or prefabrication.

Benefits of using the same CAD software. The One CAD solution in Company G, despite using several CAD tools at different design stages and disciplines, is achieved after the hull model has been integrated into the outfitting model. The rest of the modeling work happens in the integrated model. The key advantages of using this approach in Company $\mathrm{G}$ are (1) Interoperability among different design models, and (2) Comprehensive collision detection, where collision detection is firstly carried out automatically by CAD software and then performed by designers, i.e., the designers need to find out the critical collisions among the ones detected by the software.

\section{Limitations of the One CAD solution}

Despite the key benefits of using the One CAD solution, the following limitations have triggered the interest of these shipbuilding professionals in seeking insights from BIM usage in AEC.

No open standard: There is no open standard in shipbuilding industry. Although the One CAD solution reduces the interoperability requirements, it can lock shipyards to specific proprietary tools. This also reduces the ability of different shipyards to benefit from the tools and technical developments developed by the others.

Interior design still in 2D: Currently, interior design is the only design discipline that is carried out with 2D CAD tools. As explained by Interviewee 8, the lag of interior design is mainly due to the fact that most of the ships constructed are not for cruising.

Integration with other software applications in Finnish shipbuilding industry: Interviewees reported that besides CAD software used for design, there are other software systems used for functions such as project management, document management, material management, etc. and processes such as reporting and checking, scheduling, and cost estimation. Therefore, it is important that these tools can smoothly integrate with the 3D CAD tools, which is not the case currently.

\section{Discussion and implications}

Four BEPs were identified through interviews with BIM experts, i.e., clash detection, visualization, quantity takeoff and scheduling. Based on discussions with shipbuilding professionals, it was found that there are already several similar or more advanced 
practices enabled by 3D CAD in shipbuilding industry. Identified best BEPs and similar practices enabled by 3D CAD include:

Collision detection: In both AEC and shipbuilding industry, collision detection is an essential practice to find out possible collisions between different models and thus to ensure the integration of these models is carried out successfully. Although there are three types of clashes that BIM software can detect, and collision detection only refers to the detection of hard clash, it is likely that 3D CAD is at a more advanced stage of collision detection than BIM. This is mainly because collision detection in shipbuilding industry is more complicated than that in AEC.

Three factors have contributed to a higher degree of complexity of collision detection in shipbuilding industry. First of all, there are usually higher number of systems in ships. Secondly, ships have greater space constraints and the utilization of space is more compacted in shipbuilding than in AEC. The third factor is that collision detection in shipbuilding is carried out following stricter standards than in AEC, due to the higher safety requirements of shipbuilding. This is quite understandable, as the damage can be fatal when a ship fails when sailing.

Visualization is another practice enabled by both BIM and 3D CAD, which is understood as a basic function. The benefits generated from utilizing 3D visualizations are more or less similar in AEC and shipbuilding industries. Nonetheless, for shipbuilding professionals 3D is understood as a routine or a norm rather than a benefit. On the other hand, 3D is now a trendy topic in AEC industry, indicating that the utilization of $3 \mathrm{D}$ visualization in shipbuilding industry has already come to a mature stage, whereas it is still an "in" topic in AEC industry.

Quantity takeoff: The processes of generating quantity takeoffs in AEC and shipbuilding industries are very similar as well. In both industries, the process of quantity takeoff is carried out computer-assisted. Accurate quantity information is incorporated in 3D models and thus can be easily generated and reused. However, there is likely a significant difference between shipbuilding and AEC industries regarding the accuracy of cost estimates at the very early stage of the project. As shipbuilding industry has very comprehensive data management systems, i.e., product libraries with rich historical data, cost estimates at the early stage can be made with relatively high accuracy. On the contrary, AEC industry is far behind shipbuilding regarding data management. As a result, the cost estimates made at the initial stage of traditional construction projects are rough estimates with low accuracy.

Scheduling: 4D BIM, i.e., 3D BIM models with scheduling information, including location based management, was seen as a significant innovation in the evolution of construction scheduling by the BIM experts. It creates the integration of design, location and schedule data, which is one typical feature that differentiates BIM from conventional 3D CAD. With 4D BIM, schedule conflicts (i.e., the third type of clash 4D/workflow) can be easily detected.

\section{Perceptions of "the other" industry}

In addition to the identified BEPs, another interesting finding from the interviews is the perceptions of "the other" industry that these professionals have. Although the research was originated from shipbuilding professionals' interest in learning from 
AEC about BIM, it was found during the interviews that BIM experts generally had the opposite idea, i.e., AEC industry should learn from shipbuilding. It was found through the interviews with shipbuilding professionals that BIM is a relatively new topic in shipbuilding industry. It is likely that the active promotion of BIM in recent years has greatly raised the awareness of it in not only AEC, but also other industries such as shipbuilding. In other words, regardless of the technological development of BIM, the positive image of BIM among shipbuilding professionals at least proves that the marketing of BIM has been carried out successfully.

\section{Research scope and limitations}

The results of the empirical study mainly represent the current status of BIM in Finnish AEC industry and the utilization of CAD software Finnish shipbuilding industry. Due to the qualitative research method, geographical/cultural influence, this research have following limitations: (1) Face-to-face interviews enabled the collection of more in-depth information on the topic studied, but limited the number of participants, and (2) Since the interviews were conducted within Finland, the findings therefore may be influenced by the specific perception and culture of practices in this region. For example, this research focused on benefits that have already been well established in practice. Other potential benefits such as use of digital models for maintenance and operations have been discussed in literature, but the practical realization of such benefits of BIM in Finnish AEC has been rather limited. It is likely that the results might vary slightly with a wider context.

\section{Implications}

In general, shipbuilding industry is more advanced than AEC at the adoption of CAD tools for design related tasks such as collision detection and visualization. Both BIM in $\mathrm{AEC}$ and $3 \mathrm{D} \mathrm{CAD}$ in shipbuilding can generate easy and accurate quantity takeoffs, initial cost estimates of shipbuilding projects can be made with higher accuracy than AEC projects due to shipbuilding's well-maintained historical data. The only exception is scheduling. Although it is unclear whether the scheduling function of BIM is better than that of the project management software adopted in shipbuilding, AEC industry is at a more advanced stage than shipbuilding, especially with approaches such as location based management systems (Kenley 2006).

In addition, there is a fundamental difference between the understanding of the roles of BIM and 3D CAD from AEC and shipbuilding industries. In shipbuilding industry, $3 \mathrm{D}$ CAD is only for design. Other tasks such as scheduling, estimating, and product information management are carried out with other specific software systems. On the contrary, in AEC industry, BIM is much more than a design tool. Although 3D BIM is essentially 3D CAD, multiple dimensions such as scheduling (the $4^{\text {th }} \mathrm{D}$ ), estimating (the $5^{\text {th }} \mathrm{D}$ ), and building lifecycle information (the $6^{\text {th }} \mathrm{D}$ ) can be added to 3D BIM to make a comprehensive building lifecycle management tool. 


\section{References}

Autodesk. "Model Based Estimating and Quantity Takeoff." Design Academy. Autodesk, n.d. Web. 15 Mar. 2015. <http://academy.autodesk.com/library/bim-curriculumconstruction/model-based-estimating-and-quantity-takeoff $>$.

Azhar, Salman. "Building information modeling (BIM): Trends, benefits, risks, and challenges for the AEC industry." Leadership and Management in Engineering 11.3 (2011): 241-252.

Baba, Yasunori, and Kentaro Nobeoka. "Towards knowledge-based product development: the 3-D CAD model of knowledge creation." Research policy 26.6 (1998): 643-659.

Barlish, Kristen, and Kenneth Sullivan. "How to measure the benefits of BIM-A case study approach." Automation in AEC 24 (2012): 149-159.

Becerik-Gerber, Burcin, and Samara Rice. "The perceived value of building information modeling in the US building industry." Journal of information technology in Construction 15.2 (2010): 185-201.

Buildoffsite, 2011. Building Information Modelling (BIM) Seminar. Buildoffsite,London . (22nd September 2011).

CRC AEC Innovation. (2007). Adopting BIM for Facilities Management: Solutions for Managing the Sydney Opera House, Cooperative Research Center for AEC Innovation, Brisbane, Australia.

Kim, Hongtae, et al. "Applying digital manufacturing technology to ship production and the maritime environment." Integrated Manufacturing Systems 13.5 (2002): 295-305.

Kim, Minsung, et al. "A vision-based system for monitoring block assembly in shipbuilding." Computer-Aided Design 59 (2015): 98-108.

Lu, Wilson WS, and Heng Li. "Building information modeling and changing construction practices." Automation in Construction 20.2 (2011): 99-100.

Okumoto, Yasuhisa, Kentaro Hiyoku, and Noritaka Uesugi. "Simulation Based Production Using 3-D CAD in Shipbuilding." International Journal of CAD/CAM 6.1 (2009).

Roh, Myung-Il, and Kyu-Yeul Lee. "Generation of production material information for a building block and simulation of block erection for process planning and scheduling in shipbuilding." International Journal of Production Research 45.20 (2007a): 4653-4683.

Roh, Myung-Il, and Kyu-Yeul Lee. "Generation of the 3D CAD model of the hull structure at the initial ship design stage and its application." Computers in industry 58.6 (2007b): 539557.

Sarcar, MMM, K. Mallikarjuna Rao, and K. Lalit Narayn. Computer aided design and manufacturing. PHI Learning Pvt. Ltd., 2008.

Singh, Vishal, Ning Gu, and Xiangyu Wang. "A theoretical framework of a BIM-based multidisciplinary collaboration platform." Automation in AEC 20.2 (2011): 134-144.

Solesvik, Marina Z. "A Collaborative Design in Shipbuilding: Two Case Studies." Industrial Informatics, 2007 5th IEEE International Conference on. Vol. 1. IEEE, 2007.

Solesvik, Marina Z., Tatiana Iakovleva, and Sylvia Encheva. "Simulation and optimization in collaborative ship design: Innovative approach." Cooperative Design, Visualization, and Engineering. Springer Berlin Heidelberg, 2012. 151-154.

Succar, Bilal. "Building information modelling framework: A research and delivery foundation for industry stakeholders." Automation in AEC 18.3 (2009): 357-375.

Tholen, Jochen, and Thorsten Ludwig. "Shipbuilding in Europe." Structure, Employment, Perspectives, University of Bremen, Institute Labour and Economy (2006).

Whitfield, R. I., A. H. B. Duffy, and J. Meehan. "Ship product modeling." Journal of Ship Production 19.4 (2003): 230-245. 